University of New Hampshire

University of New Hampshire Scholars' Repository

Crimes Against Children Research Center

Research Institutes, Centers and Programs

$12-2001$

\title{
Offenders Incarcerated for Crimes Against Juveniles.
}

\author{
David Finkelhor \\ University of New Hampshire - Main Campus, David.Finkelhor@unh.edu \\ Richard Ormrod \\ University of Northern Colorado
}

Follow this and additional works at: https://scholars.unh.edu/ccrc

Part of the Criminology and Criminal Justice Commons, and the Sociology Commons

\section{Recommended Citation}

Finkelhor, David and Ormrod, Richard. Offenders incarcerated for crimes against juveniles. Juvenile Justice Bulletin - NCJ191028, (pgs. 1-12). Washington, DC: US Government Printing Office.

This Article is brought to you for free and open access by the Research Institutes, Centers and Programs at University of New Hampshire Scholars' Repository. It has been accepted for inclusion in Crimes Against Children Research Center by an authorized administrator of University of New Hampshire Scholars' Repository. For more information, please contact Scholarly.Communication@unh.edu. 


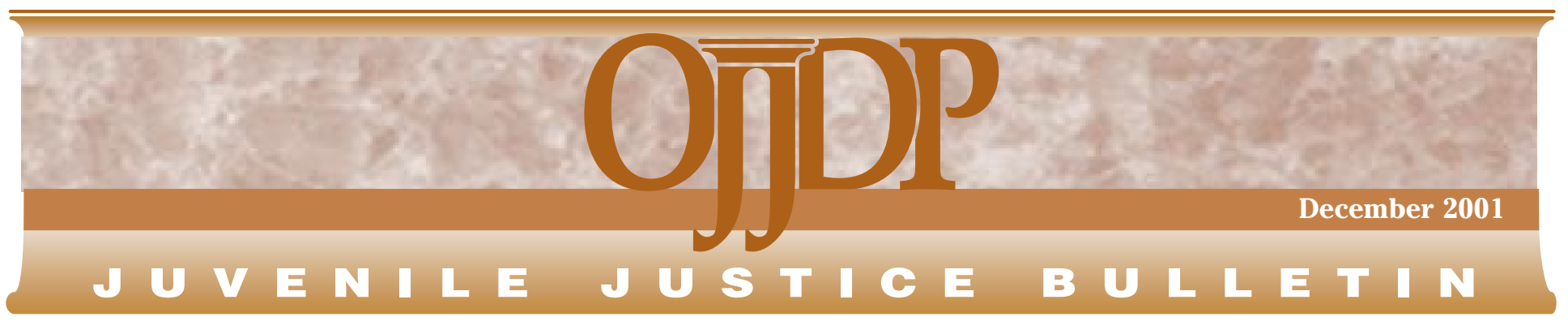

\section{Offenders Incarcerated for Crimes Against Juveniles}

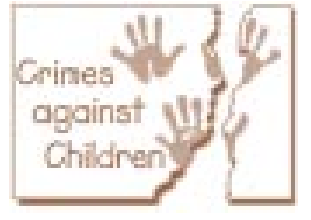

\section{David Finkelhor and Richard Ormrod}

The Office of Juvenile Justice and Delinquency Prevention (OJJDP) is committed to improving the justice system's response to crimes against children. OJJDP recognizes that children are at increased risk for crime victimization. Not only are children the victims of many of the same crimes that victimize adults, they are subject to other crimes, like child abuse and neglect, that are specific to childhood. The impact of these crimes on young victims can be devastating, and the violent or sexual victimization of children can often lead to an intergenerational cycle of violence and abuse. The purpose of OJJDP's Crimes Against Children Series is to improve and expand the Nation's efforts to better serve child victims by presenting the latest information about child victimization, including analyses of crime victimization statistics, studies of child victims and their special needs, and descriptions of programs and approaches that address these needs.

In the past two decades, media coverage of crimes committed against juveniles has grown substantially. This publicity has led to an increase in local and national efforts to report, arrest, prosecute, and incarcerate those who commit these crimes. By 1997, these offenders (hereafter called "offenders against juveniles") made up more than one-fifth of all prisoners incarcerated for violent crimes in State prisons in the United States.

Offenders against juveniles pose distinct challenges for the criminal justice system-both because of the vulnerable nature of their victims and because of society's sometimes highly charged reaction to their crimes. More information about these offenders who have been successfully prosecuted and incarcerated would give criminal justice policymakers specific insights about how to better handle these types of crimes.

This Bulletin uses data from the 1997 Survey of Inmates in State Correctional Facilities $^{1}$ (and a similar survey conducted in 1991; see Beck, 1993) to examine the characteristics of persons incarcerated for victimizing children and youth. The study's major findings include the following:

- Most offenders incarcerated for crimes against juveniles (65 percent) were sex

1 U.S. Department of Justice, Bureau of Justice Statistics and Federal Bureau of Prisons, 2000. An identical survey conducted in Federal correctional facilities found a smaller percentage of offenders against juveniles (8 percent of all violent offenders) than in State facilities. Because the small number of offenders against juveniles surveyed in Federal facilities did not produce statistically reliable information, that survey is not included in this Bulletin.

\section{A Message From OJJDP}

Public concerns arising from crimes committed against juveniles have led to increased efforts to report, arrest, convict, and imprison those who prey on youth. As a result of such enhanced activities, 1 in 5 prisoners incarcerated in State prisons for violent crime in 1997 was an offender who had victimized a youth.

Drawing on data from the 1997 Survey of Inmates in State Correctional Facilities and from an earlier 1991 survey, this Bulletin describes the characteristics of violent adult offenders who victimize juveniles and the nature of their offenses.

Trends in the population of offenders against juveniles are analyzed, and the sentences received by such criminals are reviewed. Between 1991 and 1997 , the proportion of offenders confined for violent crimes whose victims were youth increased from 19 to 22 percent.

Significant differences exist between offenders incarcerated for crimes committed against juveniles and those imprisoned for crimes against adults. For example, although only 7 percent of incarcerated offenders against adults were sex offenders, nearly two thirds (65 percent) of the incarcerated offenders against juveniles were sex offenders.

Such distinctions are explored in these pages in the hope that the information provided herein may make a difference in protecting youth from criminal predation. 


\section{The Prison Inmate Population}

Inmates within the State prison population do not represent all offenders against juveniles, nor have they committed the typical mix of crimes against juveniles that occur within a given period. State inmates represent a population that has been convicted of only the most serious offenses-those considered grave enough to warrant at least a year or more of imprisonment. Many offenders convicted of lesser offenses do not enter the State prison population. Instead, they may serve shorter sentences in local jails, be released on probation, or receive suspended sentences. Additionally, State prison populations do not include juvenile offenders placed in juvenile correctional facilities or Federal prison inmates (see footnote 1 on page 1).

Most violent offenders in State prisons in 1997 were incarcerated for homicide, robbery, assault, and sexual assault (29 percent, 27 percent, 21 percent, and 19 percent, respectively, for those inmates who provided information on victims' ages). However, not all violent offenders are sent to prison. For example, even though incarceration rates are not systematically available, studies of sexual offenders against children have shown that an average of only 53 percent of convicted offenders actually serve prison time, with the range extending from 44 to 78 percent (Chapman and Smith, 1987; Cheit, 1997; Cross, 1995; Goodman et al., 1992; Smith and Saunders, 1994).

Furthermore, inmates continually enter and leave the State prison system as they are convicted and sentenced, serve time, and get released. Some, however, stay longer than others. Because inmates with longer sentences (including life sentences) accumulate in prison over time, the State prison population at any given moment does not represent a typical year's convictions or sentences. For example, the relatively large number of inmates confined in State prisons in 1997 for homicide (29 percent of all violent offenders) reflects the longer and more severe sentences typically given for that crime rather than a high frequency of occurrence. It is important to remember that the offender population described in this Bulletin is simply a cross-section of inmates found in State prisons in 1997 and not a summary of all offenders who committed crimes during that year. ${ }^{1}$

1 An analysis of crimes that were committed against juveniles in a single year (1997), reported to police, and recorded in the National Incident-Based Reporting System, has been published in an earlier Bulletin of the Office of Juvenile Justice and Delinquency Prevention (Finkelhor and Ormrod, 2000).

offenders, whereas only a small portion (7 percent) of incarcerated offenders against adults were sex offenders.

- Most offenders incarcerated for crimes against juveniles had victimized someone in their family or household (48 percent) or an acquaintance (38 percent), whereas the majority of offenders against adults had victimized a stranger (54 percent).

- The majority of offenders incarcerated for crimes against juveniles were white (64 percent), were over 30 years old (51 percent), and had been married (56 percent); the majority of offenders against adults were nonwhite (59 percent), were under 30 (66 percent), and had never been married (60 percent).

- Offenders incarcerated for crimes against juveniles, particularly those who victimized children age 12 or younger, were more likely to have been physically or sexually abused as children.

\section{Survey of Inmates in State Correctional Facilities}

The 1997 Survey of Inmates in State Correctional Facilities is the most recent of a number of similar surveys conducted by the U.S. Census Bureau for the Bureau of Justice Statistics in 1974, 1979, 1986, and 1991. These surveys were designed to provide nationally representative data on all inmates held in State prisons.

The survey relied on personal interviews with inmates to collect information about their current offenses and sentences, criminal histories, family backgrounds and personal characteristics, prior drug and alcohol use and treatment, and prison conditions. Inmates serving time for violent crimes were also asked to provide information about their victims. ${ }^{2}$ For example, inmates were questioned about victim number, age, ethnicity, race, gender, injury, and relationship to offender. The data produced rely on inmates' memory and truthfulness. Information gathered was not separately verified against other records because, for much of the data, no corresponding official records were available. However, several measures were taken to improve survey reliability, including one-on-one interviews (interviewer and respondent only), a confidential setting, and cross-checks for internal consistency made during data collection.

In this Bulletin, differences among inmates are reported only for violent offenders who revealed their victims' ages. These inmates accounted for 89 percent of all violent crime offenders identified by the survey in 1997.

The sample design for the survey produces information that is representative of the national population of State prison inmates. ${ }^{3}$ Estimates of inmate numbers and percentages were calculated using sampling weights provided with the data.

\footnotetext{
2 The inmate survey considered the following types of offenses to be violent crimes: murder, manslaughter, kidnapping, rape, other sexual offenses, robbery, and assault. Some crimes not classified as violent by the Uniform Crime Reporting Program but which involve the victimization of individuals (e.g., blackmail, statutory rape, reckless endangerment, child endangerment, and lewdness with a child) were also included in the survey's violent crime group.
} 


\section{Identifying Offenders Against Juveniles}

The way in which information was gathered for the Survey of Inmates in State Correctional Facilities varied, depending on whether offenses were committed against single or multiple victims. Multiple-victim offenders were asked a set of questions aimed at characterizing a group of victims rather than gathering details about each one. For example, whereas a single-victim offender was asked to place that victim in a specific age group (e.g., 12 or younger), multiple-victim offenders were asked only the age of the youngest and oldest victims to characterize the overall set of victims. Similar protocols were followed to ascertain variations in gender, race, ethnicity, relationship to offender, and injury in multiple-victim incidents. This method allowed multiple-victim incidents to be recorded in a variety of ways (depending on the characteristic of particular interest), but it did not permit each victim to be individually described. For example, incidents with "any female victim" can be distinguished from those with "no female victims," and incidents with "any nonwhite or Hispanic victim" or "all minority victims" can be distinguished from those with "no minority victims."

This Bulletin identifies offenders against juveniles by following the method used by Bureau of Justice Statistics researchers in their analysis of the 1991 State Inmate Survey (Greenfeld, 1996). Single-victim offenders were considered offenders against juveniles if their victims fit into either the "12 or younger" or the " 13 to 17 " age categories. Multiple-victim offenders were considered offenders against juveniles if any of their victims fit into either of these categories. Inmates who had targeted only adults (individuals age 18 or older) were considered offenders against adults.
To compare offenders against child victims (age 12 or younger) with offenders against teen victims (ages 13-17) for multiple-victim incidents, the following definitions were established: child victimizers were those who offended against any child, teen victimizers were those who offended against any teen but no child, and adult victimizers were those who offended only against adults. Of course, designating single-victim incidents was straightforward, in that only one victim was used to designate offender status.

Some comparisons made in this Bulletin required greater specificity of victim characteristics (e.g., individual injury or relationship to offender). These comparisons were based only on singlevictim offenders (see figures 6 and 7 on page 7). About three-quarters of all incarcerated violent offenders had victimized a single person.

\section{Characteristics of Violent Offenders Against Juveniles}

In 1997, offenders against juveniles made up 22 percent of prisoners incarcerated in State prisons for violent crimes. The victims of these offenders were evenly divided between children age 12 or younger (11 percent of offenders) and teens ages 13 to 17 (11 percent of offenders) (figure 1). The distribution of offenders against juveniles, however, was not uniform by offense type; instead, offenders against juveniles accounted for a large majority of the incarcerated sex offenders (71 percent) and a rather small minority of the assault (13 percent), homicide (10 percent), and robbery (4 percent) offenders. ${ }^{4}$

In other words, most incarcerated offenders against children (72 percent) and

\footnotetext{
3 The survey followed a stratified two-stage sample selection procedure, which did not yield a simple random sample. Consequently, statistical significance testing performed in this analysis followed recommendations of the Bureau of Justice Statistics and used generalized variance estimates included in the data set for the calculation of variances (U.S. Department of Justice, Bureau of Justice Statistics and Federal Bureau of Prisons, 2000).
}

${ }^{4}$ All differences among offenders against children, teenagers, and adults described in the text or shown in the figures are significant at the $\mathrm{p}<.05$ level.

\section{Figure 1: Violent Offenders in State Prisons, by Type of Offense and Age of Victims, 1997}

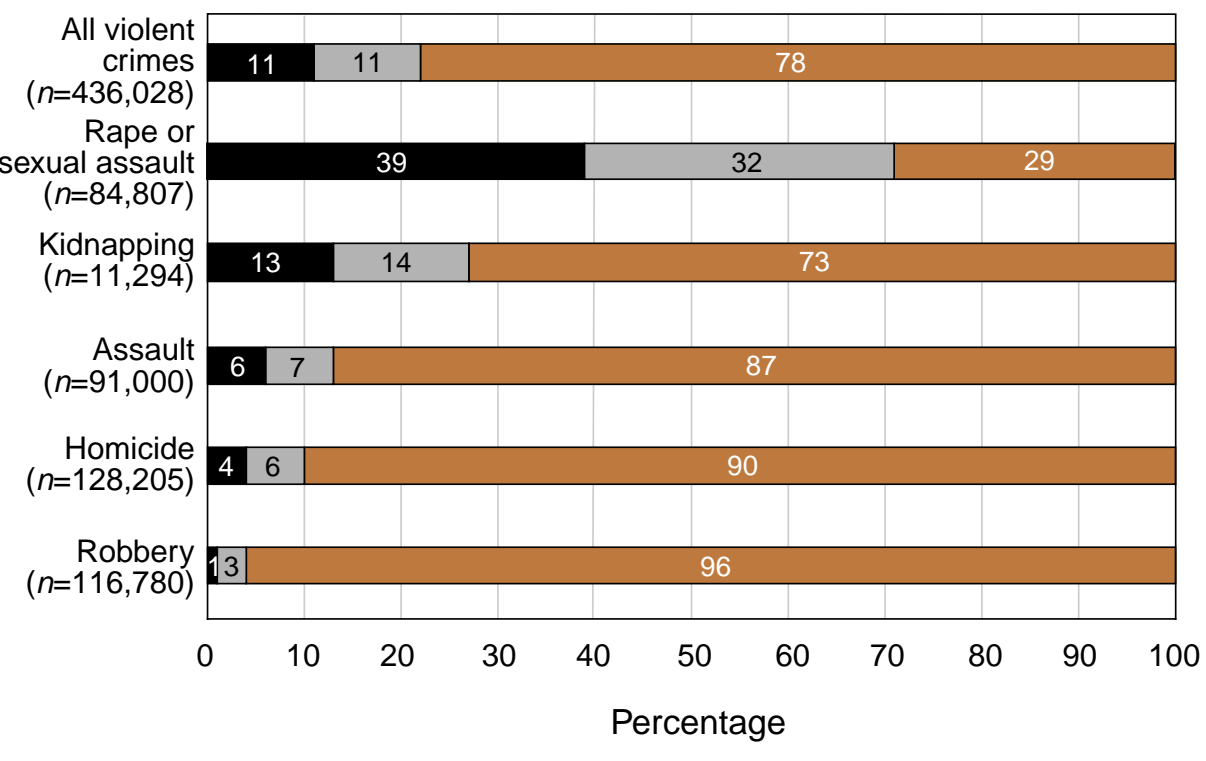

Victim age 12 or younger

Victim age 13-17

Victim age $18+$

Note: The total number of violent crimes is greater than the sum of the crimes shown because a small number of offenders convicted of nonviolent crimes, such as statutory rape, also answered questions about victims.

Source: 1997 Survey of Inmates in State Correctional Facilities, U.S. Department of Justice, Bureau of Justice Statistics and Federal Bureau of Prisons. 
Figure 2: Offense Distribution for Violent Offenders in State Prisons, by Age of Victim, 1997

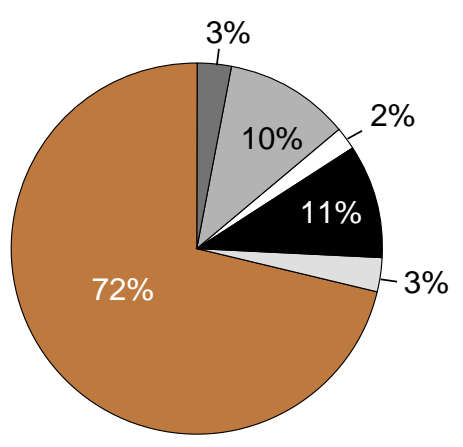

Victim Age 12 or Younger $(n=46,850)$

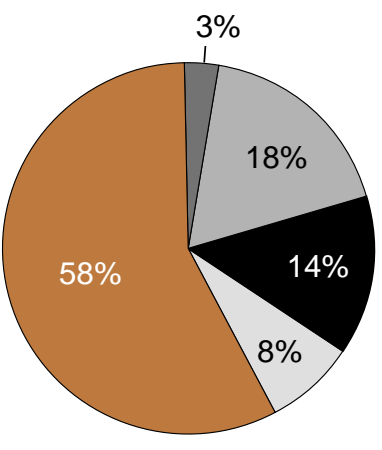

Victim Age 13-17 $(n=46,913)$

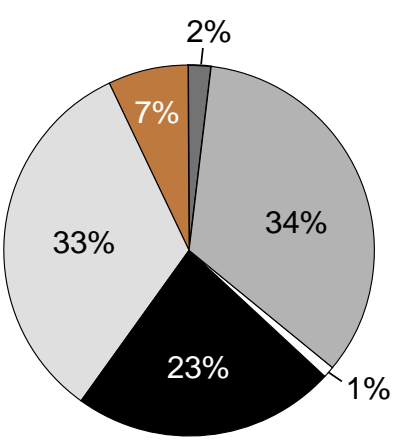

Victim Age 18+ $(n=342,265)$

Rape or sexual assault Kidnapping

Homicide

Other violent crimes

Assault

Robbery

Note: Percentages may not total 100 due to rounding.

Source: 1997 Survey of Inmates in State Correctional Facilities, U.S. Department of Justice, Bureau of Justice Statistics and Federal Bureau of Prisons.

Figure 3: Victim Age Distribution for Violent Offenders in State Prisons, by Offender Race, 1997

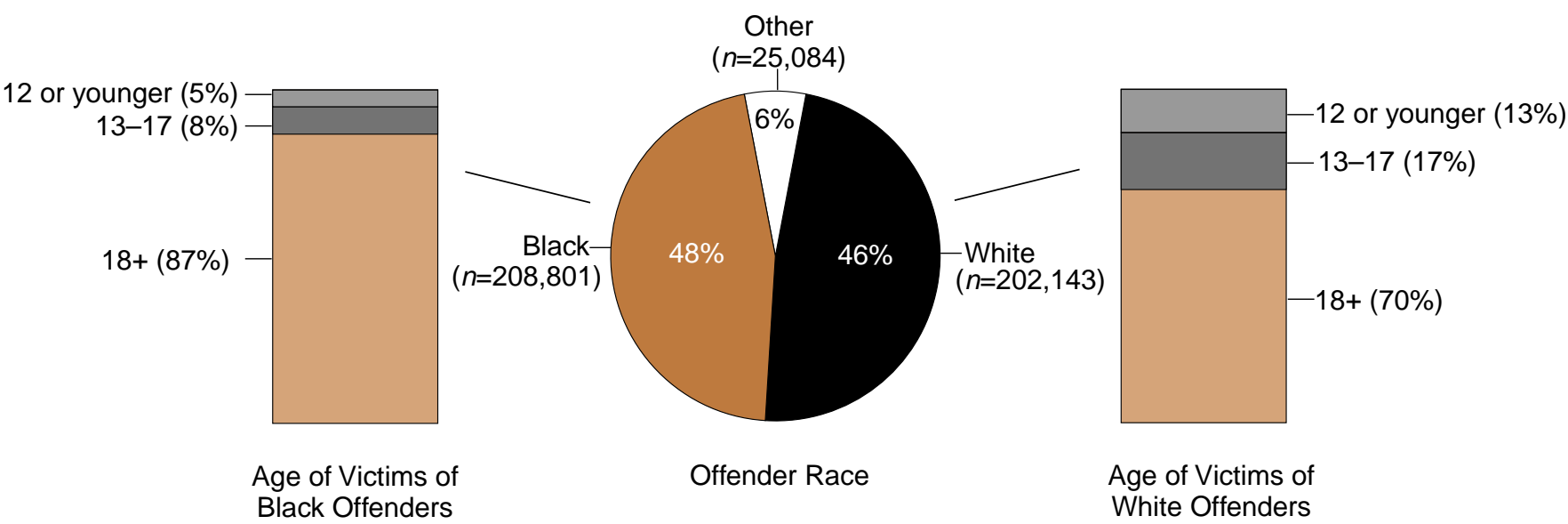

Source: 1997 Survey of Inmates in State Correctional Facilities, U.S. Department of Justice, Bureau of Justice Statistics and Federal Bureau of Prisons.

most incarcerated offenders against teens (58 percent) were in prison for committing sex crimes (figure 2). In contrast, only 7 percent of offenders against adults had committed sex crimes, and larger percentages of offenders against adults had committed homicides (34 percent), robberies (33 percent), and assaults (23 percent).

Offenders against juveniles in State prisons differed from offenders against adults in many other ways, including race, gender, age, and marital status. The majority of offenders against juveniles were white; they accounted for 73 percent of those who had victimized children and 56 percent of those who had victimized teens. In contrast, the majority of incarcerated offenders against adults (59 percent) were nonwhite. Although the overall prison population of violent offenders was almost equally divided between white and black inmates, more white offenders (30 percent) than black offenders (13 percent) had committed crimes against juveniles (figure 3 ).
In terms of gender, women made up only a small fraction (4 percent) of the incarcerated population for violent crimes of any sort. However, they were somewhat overrepresented (6 percent) among offenders against children age 12 or younger and underrepresented (only 1 percent) among those who had victimized teens ages 13-17. It is unclear whether this representation is due to the actual incidence of crimes committed by females or to the way in which the justice system deals with their crimes. 


\section{Figure 4: Age of Violent Offenders in State Prisons at the Time of} Arrest, by Age of Victim, 1997

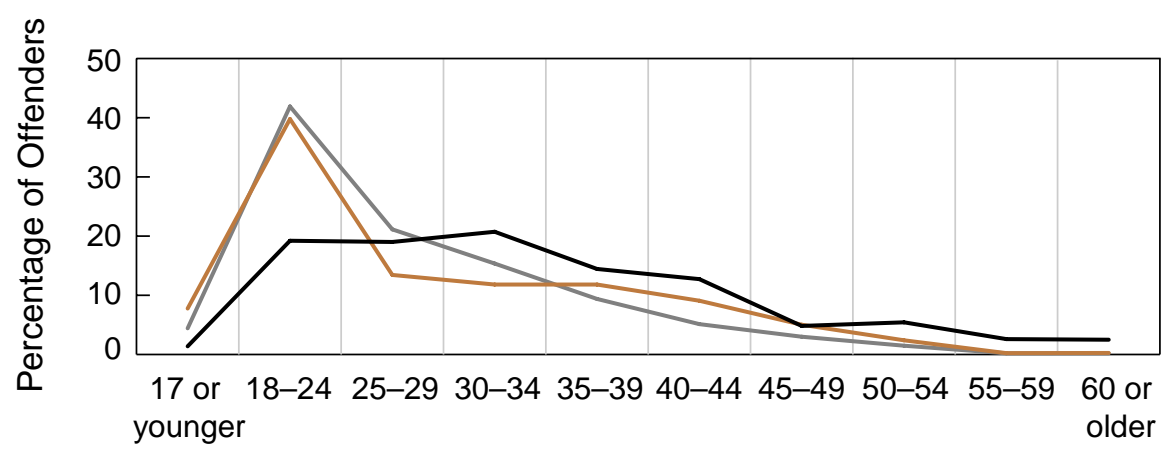

\section{Offender Age at Arrest}

$$
\text { — Victim age } 12 \text { or younger — Victim age 13-17 — Victim age 18+ }
$$

Note: Area under each line represents 100 percent of offenders for each victim age group. Source: 1997 Survey of Inmates in State Correctional Facilities, U.S. Department of Justice, Bureau of Justice Statistics and Federal Bureau of Prisons.

\section{Figure 5: Victim Age Distribution for Violent Offenders in State Prisons, by Offender Age at Time of Arrest, 1997}

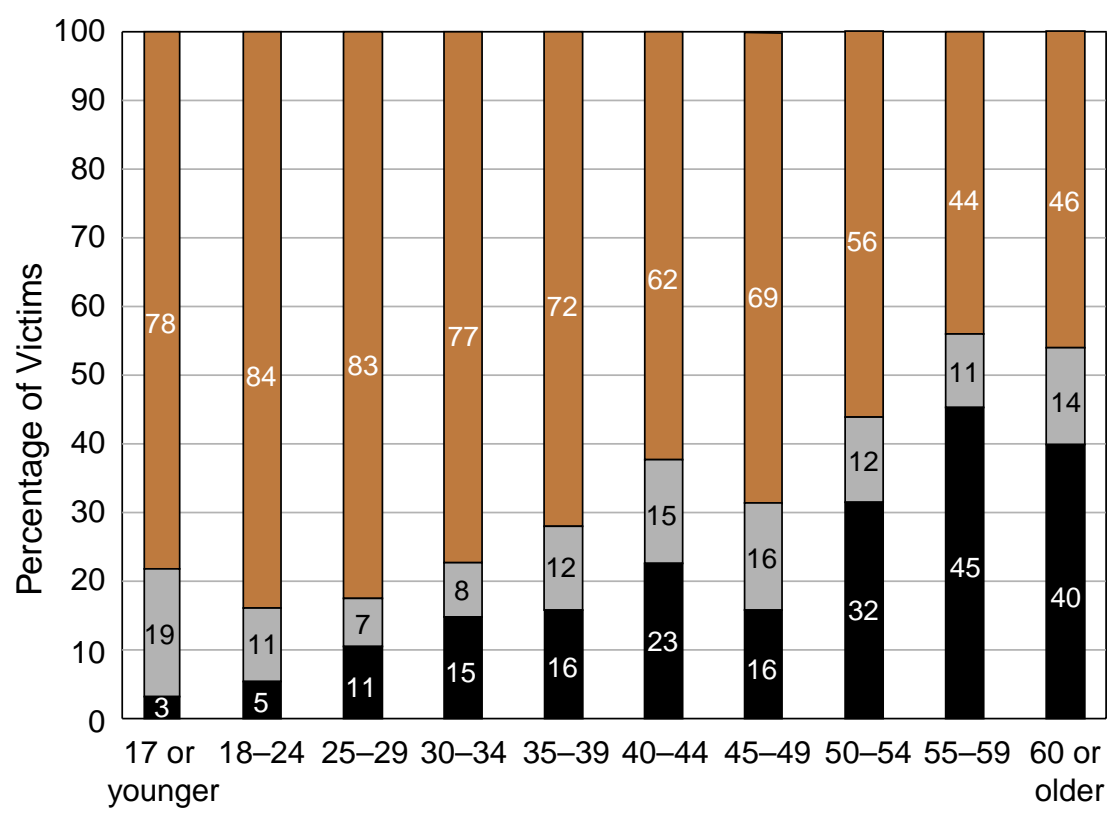

\section{Offender Age at Arrest}

Victim age 12 or younger

Victim age 13-17

Victim age 18+

Note: Percentages may not total 100 due to rounding.

Source: 1997 Survey of Inmates in State Correctional Facilities, U.S. Department of Justice, Bureau of Justice Statistics and Federal Bureau of Prisons.
Overall, offenders against juveniles in State prisons were older (51 percent over age 30) than offenders against adults (only 34 percent over age 30 ) at the time of their arrest. This difference is almost entirely attributable to the older age distribution of offenders who victimized children (age 12 or younger) rather than teens (ages 13-17) (figure 4). Among offenders against children, 62 percent were over 30 and fewer were ages 18 to 24 , which was the peak age group for inmates who victimized adults and teens.

In other words, the older the violent offenders were at the time of their arrest, the more likely they were to have offended against juveniles (figure 5). Fifty-four percent of offenders arrested at age 60 or older had committed crimes against juveniles compared with 16 percent of offenders age 18 to 24 at the time of arrest. Also, older incarcerated offenders were more likely to have victimized children than teens. Of the sex offenders older than 60,100 percent had committed crimes against juveniles.

In addition to being typically older and white, incarcerated offenders against juveniles were also more likely to have been married (56 percent) than offenders against adults (40 percent). The percentage of offenders who had ever been married was particularly high (65 percent) among those who victimized children age 12 and under. Offenders against juveniles were also more likely than offenders against adults to have been employed during the month before their arrest (76 percent versus 69 percent).

\section{Offense Characteristics}

One of the most dramatic differences between incarcerated offenders against juveniles and offenders against adults was the offender/victim relationship. Offenders against juveniles were much more likely to have victimized a family member or an acquaintance, whereas most offenders against adults had victimized strangers (figure 6, page 7).

Offenders' relationships to their victims also varied between inmates who victimized children and inmates who victimized teens. Offenders against children had most often victimized their own children or stepchildren (40 percent) or another young relative (18 percent); very few (5 percent) had victimized a stranger. Among offenders who victimized teens, a considerable number had victimized their own children (21 percent) or another 
relative ( 9 percent), and another 9 percent had victimized an intimate partner, such as a spouse or girlfriend. The proportion of offenders who victimized teenage strangers rose to 22 percent. Among offenders against adults, the proportion that had victimized strangers increased to 54 percent and the proportion that victimized relatives or intimates decreased to 16 percent.

It is important to keep in mind that these victim/offender patterns vary somewhat, depending on the type of offense, and that offenders against juveniles were primarily incarcerated for sex offenses. Among sex offenders, those who victimized both children and teens were more likely to have offended against their own children and relatives, and they were less likely to have offended against strangers (figure 7). Among offenders incarcerated for homicide, however, only those who had victimized children (and not teens) had victimized within their families. Within the inmate sample, no incarcerated offenders who killed teens had killed their own children, and only 8 percent had killed another relative. These percentages reflect the typical patterns of these offenses. Intrafamilial sexual abuse of a teen, particularly of a daughter by a father or stepfather, is a relatively frequent sex crime, but when parents kill their children, they usually kill infants and young children-rarely are teens the victims (Finkelhor and Ormrod, 2000; Finkelhor and Ormrod, 2001). Offenders who had killed teens or adults, however, were more likely than offenders against children to target strangers.

Offenders against juveniles and offenders against adults also differed in regard to the gender of their victims. Most offenders against juveniles (76 percent) had female victims. The majority of offenders against adults (64 percent) had male victims. In part, this reflects the fact that most offenders against juveniles committed sex crimes, which typically have female victims (Finkelhor and Ormrod, 2000). However, even for the crime of homicide, offenders against children were more likely to have female victims than offenders against adults. For example, 53 percent of offenders who killed children age 12 or younger targeted females, but only 30 percent of offenders who killed teens and 26 percent of offenders who killed adults had female victims. ${ }^{5}$ Sexual assaults showed a somewhat opposite pattern. Offenders who victimized juveniles (children age 12 or younger and teens ages 13-17) were somewhat more

\footnotetext{
5 Incidents involving physical assaults (not shown) are similar to homicide incidents in terms of victim age, gender, and relationship to offender
}

likely to target males than offenders who victimized adults (16 percent and 7 percent, respectively, versus 3 percent).

Offenders against juveniles in State prisons also differed from offenders against adults in other aspects of the crimes they committed. Few of the crimes committed by offenders against juveniles involved weapons ( 8 percent of crimes against children and 27 percent of crimes against teens, compared with 51 percent of crimes against adults). Crimes committed by offenders against juveniles also were less likely to involve multiple offenders and multiple offenses. These differences reflect the fact that adults do not need to rely on weapons and assistance from other offenders to commit crimes against juveniles, who are usually smaller than their offenders and often under their care and authority. Offenders against juveniles were also less likely than offenders against adults to have used drugs or alcohol during their offenses (39 percent for offenders against children, compared with 45 percent and 55 percent for offenders against teens and adults, respectively). These considerations may have contributed to the finding that offenders against juveniles were less likely to inflict injuries on their victims (14 percent of child victims and 28 percent of teen victims were injured, compared with 70 percent of adult victims).

\section{Comparison of Sentences of Offenders Against Juveniles and Offenders Against Adults}

Concern that the criminal justice system treats offenders against juveniles more leniently than offenders against adults can be only partially addressed with the data available in the 1997 Survey of Inmates in State Correctional Facilities. A comparison of sentence severity must take into account several important limitations of these data.

First, although the sentences of inmates in State prisons can be compared, these prisoners do not represent all the offenders who come into contact with the criminal justice system. In general, the offenses committed by State prisoners are those the justice system considers the most serious. However, many convicted offenders are given suspended sentences, probation, or shorter sentences that are served in local jails rather than prisons. Additionally, there are other offenders who, for one reason or other, are not arrested or charged with crimes at all. Whether offenders against juveniles are treated more leniently than offenders against adults during the earlier stages of the legal process cannot be determined from the information presented in the inmate survey.

Second, offenders are incarcerated in State prisons for a variety of violent offenses, not all of which, by definition, can have both adult and juvenile victims. For example, the survey includes the crimes of statutory rape, lewd act with children, and child abuse, which have no adult victims, and assaulting a public officer, which has no juvenile victims. These offenses do not provide equivalent (or comparable) sentences for both offenders against adults and offenders against juveniles. This Bulletin limits sentence comparisons to inmates whose offenses can have victims in either age group.

Third, the sentences examined in the survey vary in many ways, each of which must be taken into account when making comparisons. For example, the survey designates one offense for each inmate as the "controlling offense" and records sentence details for that offense only. If an inmate is incarcerated for a single offense, that offense is the controlling offense. If an inmate is incarcerated for multiple offenses, the controlling offense is the crime that results in the longest or most severe maximum sentence. Also, because maximum sentences can be reported either as a specific length of time (term sentence) or as a life or death sentence, two different approaches were used to compare sentence severity. The first compares all inmates by juxtaposing those serving term sentences (less severe) with those serving life or death sentences (more severe). The second approach considers only inmates serving term sentences and measures sentence severity by calculating the length of the sentence. 
Figure 6: Distribution of Offender/Victim Relationship for Violent Offenders in State Prisons, by Age of Victim, 1997

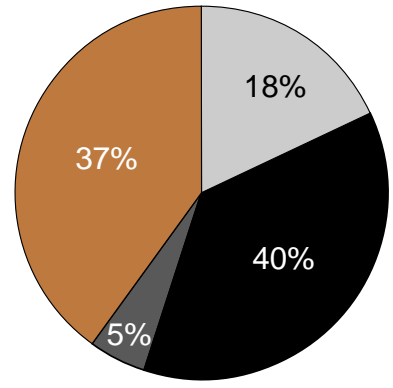

Victim Age 12 or Younger

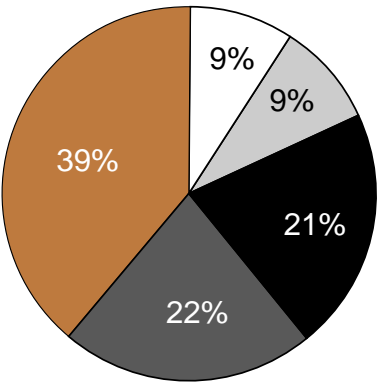

Victim Age 13-17

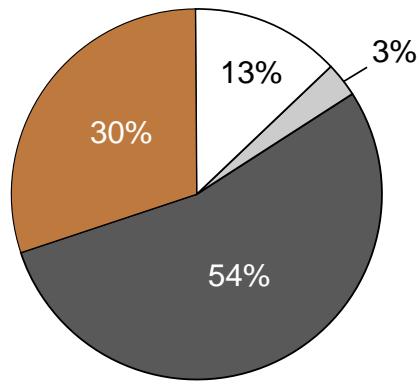

Victim Age 18+

Own child or stepchild $\quad \square$ Stranger

Acquaintance

Spouse or intimate partner

Other relative

Note: Data are based on single-victim incidents only.

Source: 1997 Survey of Inmates in State Correctional Facilities, U.S. Department of Justice, Bureau of Justice Statistics and Federal Bureau of Prisons.

\section{Figure 7: Distribution of Offender/Victim Relationship for Sex and Homicide Offenders in State Prisons, by Age of Victim, 1997}

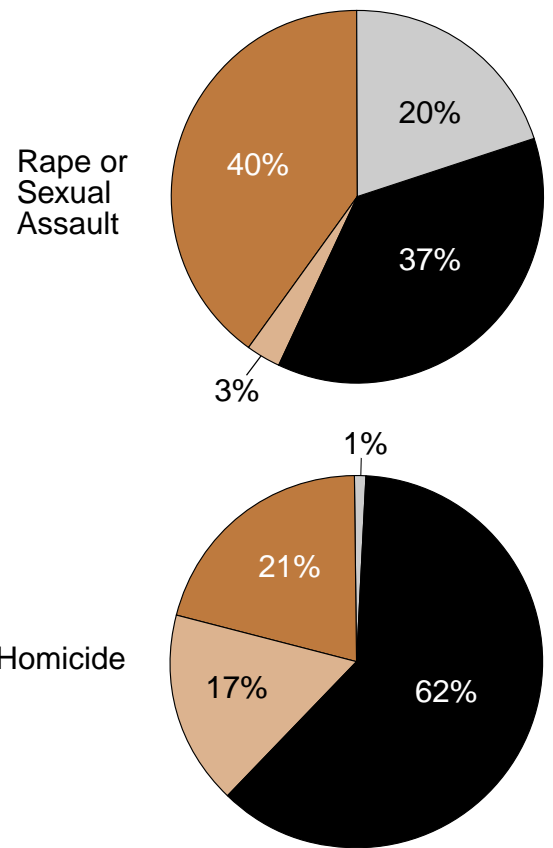

Victim Age 12 or Younger
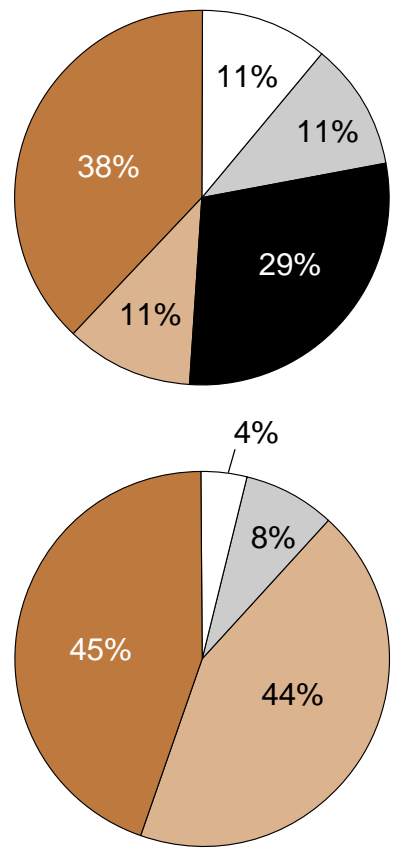

Victim Age 13-17
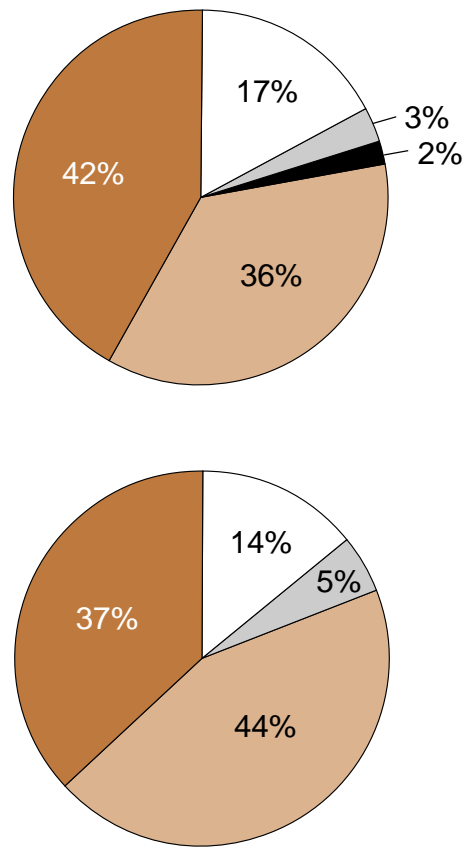

Victim Age 18+

Own child or stepchild $\quad \square$ Stranger

Acquaintance

Spouse or intimate partner

Other relative

Note: Data are based on single-victim incidents only.

Source: 1997 Survey of Inmates in State Correctional Facilities, U.S. Department of Justice, Bureau of Justice Statistics and Federal Bureau of Prisons. 


\section{Figure 8: Distribution of Sexual and Physical Abuse History of Violent Offenders in State Prisons,}

by Age of Victim, 1997

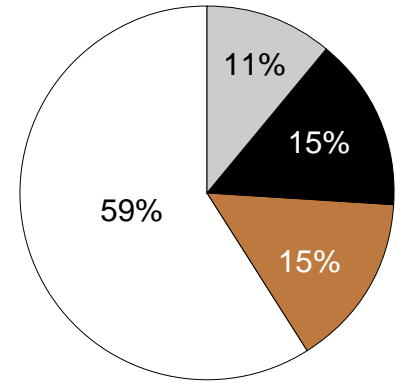

Victim Age 12 or Younger

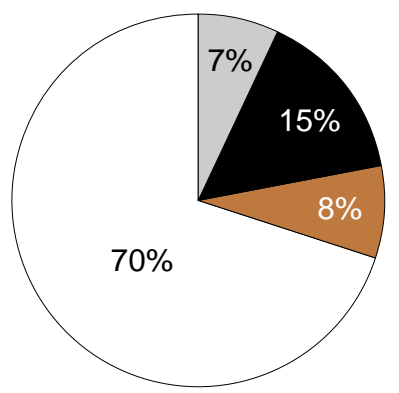

Victim Age 13-17

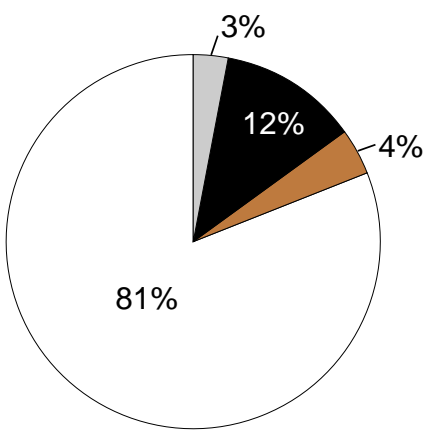

Victim Age 18+

Sexual abuse

Physical abuse

Both

Not abused

Source: 1997 Survey of Inmates in State Correctional Facilities, U.S. Department of Justice, Bureau of Justice Statistics and Federal Bureau of Prisons.

Table 1: Typical Characteristics of Violent Offenders in State Prisons, by Victim Age, 1997

\begin{tabular}{lll} 
Characteristic & \multicolumn{1}{c}{$\begin{array}{c}\text { Offenders Against } \\
\text { Juveniles }\end{array}$} & \multicolumn{1}{c}{$\begin{array}{c}\text { Offenders Against } \\
\text { Adults }\end{array}$} \\
\hline Crime & Sex offenses (65\%) & Violent nonsex offenses (93\%) \\
Race & White (64\%) & Nonwhite (59\%) \\
Age at arrest & Over age 30 (51\%) & Under age 30 (66\%) \\
Marital status & Ever married (56\%) & Never married (60\%) \\
Relation to victim & Relative/intimate (48\%) & Stranger (54\%) \\
& Acquaintance (38\%) & \\
Weapon & No weapon (82\%) & Weapon (51\%)
\end{tabular}

Source: 1997 Survey of Inmates in State Correctional Facilities, U.S. Department of Justice, Bureau of Justice Statistics and Federal Bureau of Prisons.

\section{Offender History}

Offenders against juveniles were less likely than other offenders to be recidivists. Although the majority of incarcerated violent offenders in State facilities are recidivists, the recidivism rates were lower for offenders against children (59 percent) and teens (61 percent) than for offenders against adults (72 percent).

In addition to questions about criminal history, the survey also asked prisoners whether they had been physically or sexually abused as children (answers were uncorroborated by other sources). Offenders against juveniles reported being victims of physical or sexual abuse more often than inmates who had committed crimes against adults only (figure 8).
Perhaps a history of physical and sexual abuse is more common among those who commit physical and sexual crimes against juveniles than it is among other violent criminals. However, in trying to understand their crimes, these offenders may have had more occasion to remember victimizations similar to those they committed, or they may have used their childhood experiences to defend their criminal behavior in court.

\section{Summary of Differences}

As a group, incarcerated offenders against juveniles are clearly different from the much larger group of offenders against adults. Table 1 highlights the most dramatic contrasts. Offenders against juveniles were mostly white, older, previously married men who primarily had committed sex offenses against female relatives, intimates, or acquaintances, without using weapons. Conversely, offenders against adults were predominantly nonwhite men, under 30 , who had never married and primarily had committed violent, nonsexual offenses with weapons against male strangers.

Given the source of the data, these contrasts apply only to incarcerated offenders and cannot necessarily be extrapolated to describe offenders against juveniles and adults outside State prison populations. Some groups (for example, older, white physical assaulters) may not be reported, arrested, prosecuted, or incarcerated as often as other offenders for a variety of reasons, and such system biases may create or accentuate the contrasts found among the incarcerated population. Nonetheless, it is noteworthy that a substantial segment of the incarcerated population is imprisoned for crimes against juveniles. The ways in which these offenders differ from the rest of the prison population are also noteworthy. In particular, offenders against juveniles have less often committed the kinds of crimes that most terrify communitiescrimes such as assaults by strangers that involve weapons and physical injuries. Given these differences, this offender subpopulation likely constitutes a clearly differentiated group within prisons and may experience both advantages (employment experience, family ties, and racial favoritism) and disadvantages (sex crime stigma 
and physical inferiority) in the prison environment (Musk and Swetz, 1997; Toch, 1977).

\section{Trends in the Victimizers of Juveniles Population}

The number of offenders against juveniles incarcerated in State prisons was substantially higher in 1997 than it was in 1991, the last year that a State inmate survey had been conducted-up from 61,040 in 1991 to 93,760 in 1997 . The higher figure, however, is mostly accounted for by a large increase (33 percent) in the total number of incarcerated violent offenders with victims of any age (figure 9). There was also a small but significant increase in the proportion of all violent offenders who were offenders against juveniles (from 19 to 22 percent).

Between 1991 and 1997, the number of offenders against juveniles incarcerated for homicide rose from 5,793 to 12,746 . As a result, the percentage of homicide offenders represented within all incarcerated offenders against juveniles rose from 10 to 14 percent. The number of sex offenders against juveniles also increased, rising from 42,933 to 60,549 . However, because the number of sex offenders increased at a slower rate than the number of homicide offenders, the relative percentage of sex offenders decreased (from 71 to 65 percent).

\section{Sentences for Offenders Against Juveniles}

Advocates for child victims, in particular, sometimes argue that the justice system is too lenient on victimizers of children. Cases involving light sentences for child murderers and sex offenders have received substantial newspaper coverage (Kirk, 1997; Wolfe, 1998) and prompted some States to draft new legislation, such as "homicide by child abuse" laws that allow prosecutors to charge offenders against children with more serious crimes

(Phipps, 1999).

Assessing sentencing severity for offenders against children, however, is difficult. As described above, offenders against children and teens tend to differ from other offenders, and these differences may affect sentence severity. For example,

\section{Figure 9: Number of Violent Offenders in State Prisons, by Age of Victim, 1991 and 1997}

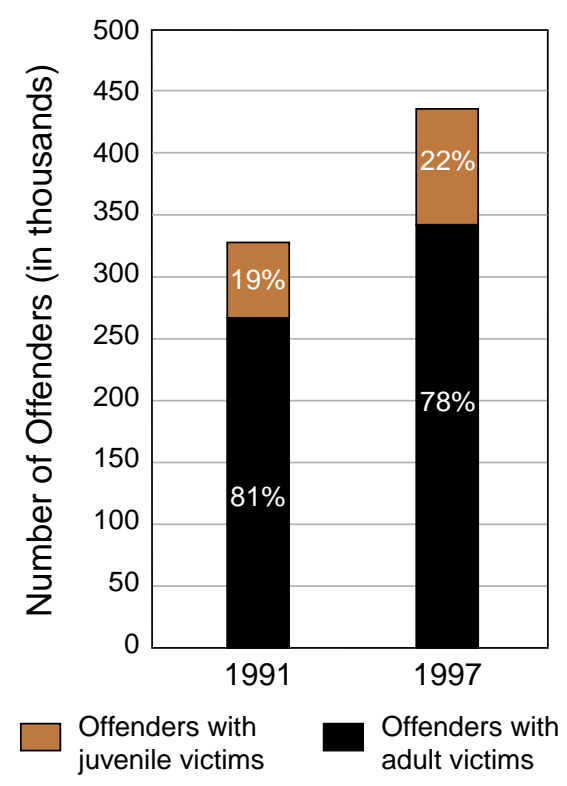

Note: Only violent offenders who reported a victim's age are included. Differences in juvenile and adult victim proportions for 1991 and 1997 are significant at the $p<.05$ level. Between 1991 and 1997, the number of violent offenders in State prisons increased by $33 \%$ (from 327,960 to 436,030 ).

Source: Greenfeld, 1996; 1997 Survey of Inmates in State Correctional Facilities, U.S. Department of Justice, Bureau of Justice Statistics and Federal Bureau of Prisons.

compared with other offenders, victimizers of juveniles are more likely to be related to their victims, less likely to use weapons, more likely to be employed, and less likely to be recidivists-all of which might ordinarily reduce sentence severity, regardless of the victim's age (Erez and Tontodanato, 1990; Steffensmeier and Motivans, 2000; Steffensmeier, Ulmer, and Kramer, 1998). Data from the Survey of Inmates in State Correctional Facilities offer information on sentence severity that can be used to assess whether offenders against juveniles receive unusually lenient sentences. Although limited in some respects (see sidebar on "Comparison of ...," page 6), this information describes the personal and criminal characteristics of offenders against juveniles that may be taken into consideration during sentencing.
Sentence severity findings are mixed when offenders against children, teens, and adults are directly compared without any adjustments. Data show that offenders against children and teens are somewhat less likely than offenders against adults to receive life or death sentences for their crimes (figure 10, page 10). Twelve percent of offenders against children, 9 percent of offenders against teens, and 17 percent of offenders against adults received life or death sentences. However, because offenses against children and teens are often sex crimes and offenses against adults are often homicides, it is important to view these figures within the context of specific offenses. When viewed in this way, the only difference between child, teen, and adult victimizers appears to be that offenders against teens are less likely to receive life or death sentences for sex crimes.

Term sentence lengths (i.e., excluding life or death sentences) for offenders were not as varied (figure 10). The number of months received by offenders against juveniles and offenders against adults were fairly similar (examining gross differences without adjusting for offender or offense characteristics). However, offenders against children and teenagers do appear to receive lighter sentences for sex crimes than offenders against adults (180 months versus 240 months, respectively). In the case of homicides, offenders against children and teenagers appear to receive longer sentences than offenders against adults; however, the differences are not statistically significant.

Factors other than type of offense also affect sentence severity, notably, victim/ offender relationship and weapon use. For example, sentences for offenders against juveniles may have been more lenient not simply because they involved younger victims, but because those crimes involved more family members and fewer weapons. Differences such as these need to be taken into account when considering the survey's findings.

Table 2 (page 11) shows the results of an analysis in which sentences were statistically adjusted to reflect the effects of various factors, including victim characteristics, such as age, gender, and relationship to offender; offense characteristics, such as type of crime, use of weapon, and number of offenders; offender characteristics, such as gender, race, and age at arrest; and legal processing conditions, such 
as conviction by trial, use of a public defender, and presence of sentencing guidelines. ${ }^{6}$ The data clearly show that sentences for offenders against children under age 12 are not more lenient. In fact, when adjusted for specific types of offenders and crimes, these sentences are statistically indistinguishable from sentences received by offenders against adults. However, there does appear to be a systematic and fairly large tendency for offenders against teens to receive lighter sentences than other offenders. When other factors (i.e., victim, offense, offender, and legal processing) are controlled, offenders against teens are 52 percent less likely than offenders against adults to receive a life or death sentence, 82 percent less likely to receive a life or death sentence for a nonfatal sexual assault, and 33 percent less likely to receive a life or death sentence for a homicide. Offenders against teens are also likely to receive sentences that are about 2 years (25 months) shorter than those given to offenders against adults and about 7 years (87 months) shorter than those given to inmates who committed nonfatal sex offenses against adults. Homicide sentences are not significantly different in length.

Therefore, it appears that offenders against teens-not offenders against young children-receive lighter sentences. The lighter sentences in this case may be, in part, the result of negative perceptions about teen victims. Influenced by popular stereotypes about teens, judges may be prone to view teenage physical or sexual assault victims as having behaved provocatively or irresponsibly. These judgments may be mitigating factors in sentencing decisions in cases with teen victims. Other mitigating factors may occur in some crimes against teens, such as gang affiliation by the victim, that are not captured in the data. Therefore, the differences in sentencing could be due to both real features and social stereotypes. In any case, the differences in sentencing related to victim age should be researched more thoroughly.

\footnotetext{
6 A complete list of the factors considered also includes victim race and ethnicity, attempted or completed crime, injury to victim, involvement of multiple victims, use of drugs or alcohol by offender, offender employment, offender recidivism, offender abuse history, conviction for multiple offenses, sentencing as an adult, and sentencing affected by a firearms violation, a drug offense, or previous "strikes."
}

\section{Figure 10: Sentences of Violent Offenders in State Prisons, by Offense and Age of Victim, 1997}
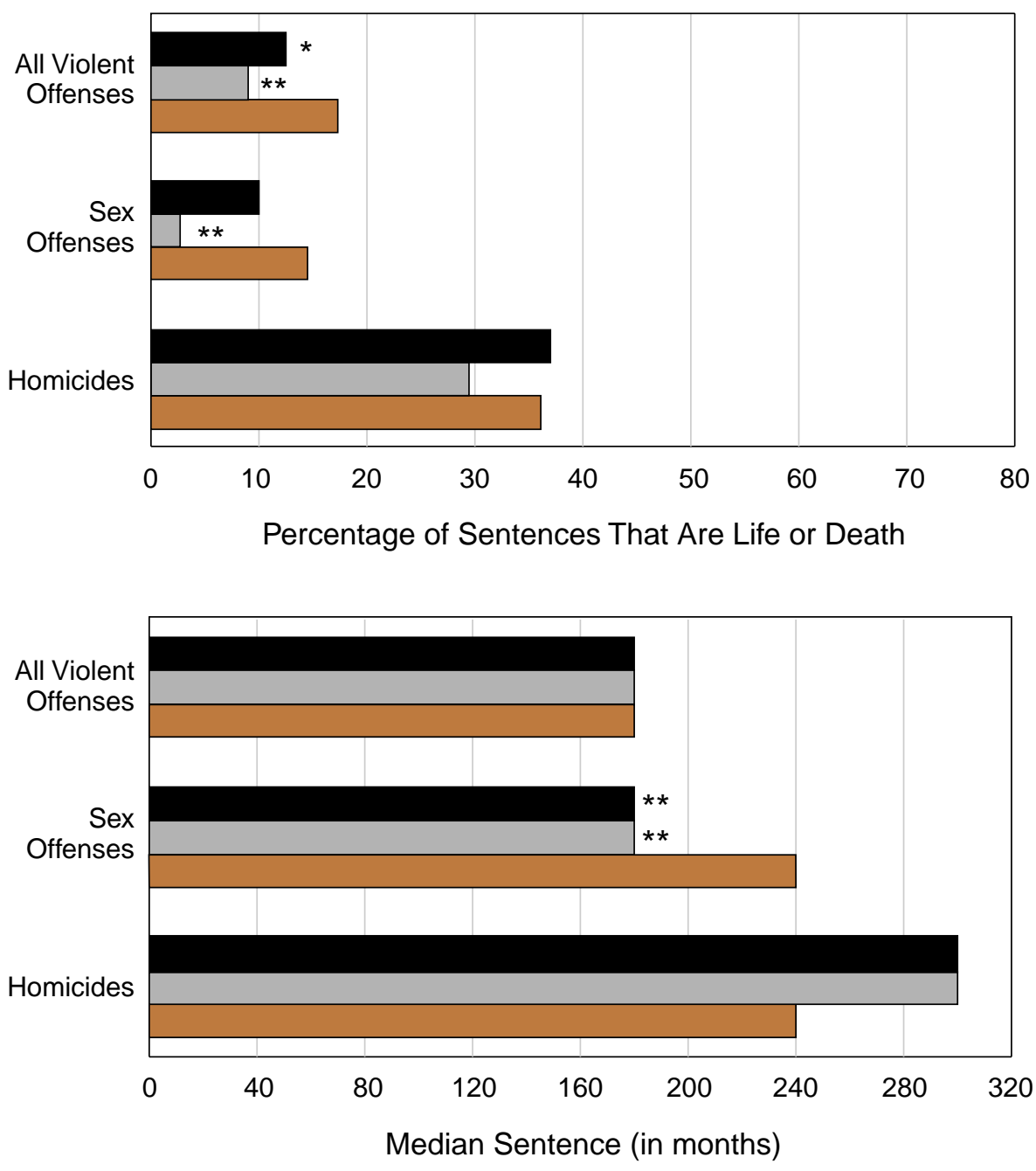

Victim age 12 or younger

Victim age 13-17

Victim age $18+$

* Different from adult victims, $p<.05$.

** Different from adult victims, $p<.01$.

Source: 1997 Survey of Inmates in State Correctional Facilities, U.S. Department of Justice, Bureau of Justice Statistics and Federal Bureau of Prisons.

\section{Conclusion}

Individuals who commit crimes against children and teens make up a large and growing segment of the population of violent offenders incarcerated in State correctional facilities. These inmates, as a group, have distinguishing features: they are disproportionately sex offenders against family members and acquaintances; they are mostly older, white, and employed; and they are less recidivistic and more likely to have been married than other incarcerated violent offenders. Given this group's distinctiveness, it is noteworthy that this segment of the prison population has generated relatively little research.

Many people have observed that sex offenders against children are strongly reviled within prison subculture and subjected to harassment and assault. For these reasons, offenders against children 


\section{Table 2: Effects of Victim Age on Sentencing}

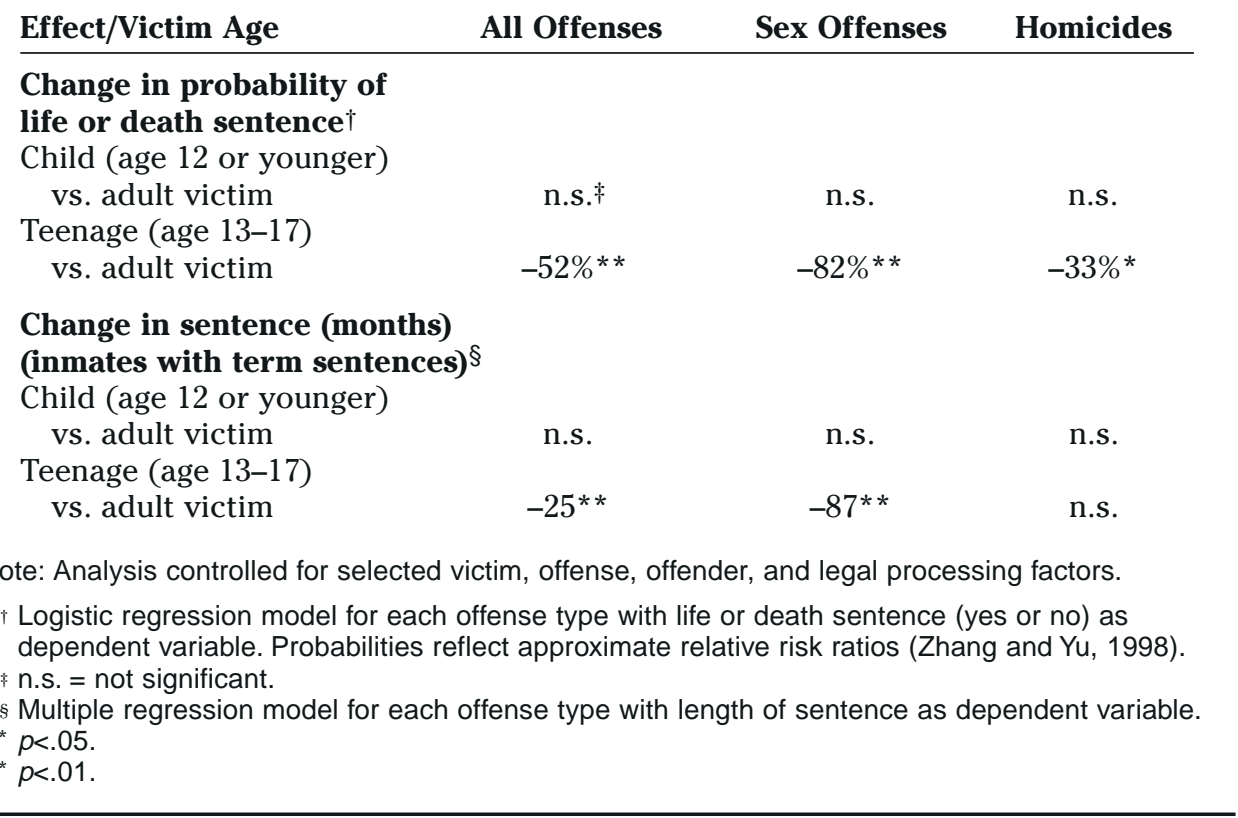

may conceal their offenses or be segregated from other inmates (Musk and Swetz, 1997). However, such generalizations certainly mask the varied experiences of different facilities and individuals. Some characteristics of this subpopulation, such as marital ties and employment experience, may work to its advantage. In addition, this population's characteristics may confer upon it differential treatment throughout the justice system, from the prosecution phase to the operation of parole boards and probation officials. These potential differences are worthy of more attention.

A form of differential treatment that has received much attention in recent years is when offenders against children are accorded overly lenient sentences, perhaps because the lives and suffering of children were insufficiently valued in judicial decisionmaking. Analysis for this Bulletin, however, suggests that when important features such as offense seriousness and offender recidivism are taken into account, offenders against children age 12 or younger do not receive more lenient sentences than other offenders. Rather, offenders against teens receive lighter sentences than might be expected, based on their offenses and criminal histories. This disparity certainly merits more attention, particularly if it stems from stereotypical views that teenage victims are in some way responsible for their own victimizations.
Although a substantial amount of research has focused on the determinants of sentencing and possible sentencing inequities (e.g., Erez and Tontodanato, 1990; Levesque, 2000; McCormick et al., 1998; Myers, 1979; Steffensmeier and Motivans, 2000; Steffensmeier, Ulmer, and Kramer, 1998; Steffensmeier and Ulmer, 1995), victim age has never been considered as a possible factor in this literature. examine how victim age affects sentencing for offender populations broader than the one examined in this analysis, which was limited to offenders sentenced to State prisons. Juvenile crime victims have not always had consistent access to the full and impartial benefits of the justice system; therefore, monitoring the justice system's response to cases involving these particular victims seems to be a

\section{References}

Beck, A.J. 1993. Survey of State Prison Inmates, 1991. Washington, DC: U.S. Department of Justice, Office of Justice Programs, Bureau of Justice Statistics.

Chapman, J.R., and Smith, B.E. 1987. Child Sexual Abuse: An Analysis of Case Processing. Washington, DC: American Bar Association.

Cheit, R.E. 1997. Child molesters in the criminal justice system: A comprehensive case-flow analysis of the Rhode Island It is particularly important that studies justified and important priority. docket. New England Journal on Criminal and Civil Confinement 23(2):267-301.

Cross, T.P. 1995. Criminal justice outcomes of prosecution of child sexual abuse: A case flow analysis. Child Abuse \& Neglect 19(12):1431-1442.

Erez, E., and Tontodanato, P. 1990. The effect of victim participation in sentencing on sentence outcome. Criminology 28(3):451-474.

Finkelhor, D., and Ormrod, R. 2000. Characteristics of Crimes Against Juveniles. Bulletin. Washington, DC: U.S. Department of Justice, Office of Justice Programs, Office of Juvenile Justice and Delinquency Prevention.

Finkelhor, D., and Ormrod, R. 2001. Homicides of Children and Youth. Bulletin. Washington, DC: U.S. Department of Justice, Office of Justice Programs, Office of Juvenile Justice and Delinquency Prevention.

Goodman, G.S., Taub, E.P., Jones, D.P.H., England, P., Port, L.K., Rudy, L., and Prado, L. 1992. Testifying in court. Monographs of the Society for Research in Child Development 57(5):1-142.

Greenfeld, L.A. 1996. Child Victimizers: Violent Offenders and Their Victims. Report. Washington, DC: U.S. Department of Justice, Office of Justice Programs, Bureau of Justice Statistics and Office of Juvenile Justice and Delinquency Prevention.

Kirk, L.M. 1997. Innocence lost: Child sexual abuse in Rhode Island. Providence Journal (February 2):A-1.

Levesque, R. 2000. Sentencing sex crimes against children: An empirical and policy analysis. Behavioral Sciences and the Law 18:331-341.

McCormick, J.S., Maric, A., Seto, M.C., and Barbaree, H.E. 1998. Relationship to victim predicts sentence length in sexual assault cases. Journal of Interpersonal Violence 13(3):413-420.

Musk, H., and Swetz, A. 1997. Pedophilia in the correctional system. Corrections Today 59(5):24-28.

Myers, M.A. 1979. Offended parties and official reactions: Victims and the sentencing of criminal defendants. The Sociological Quarterly 20:529-540.

Phipps, C.A. 1999. Responding to child homicide: A statutory proposal. Journal of Criminal Law and Criminology 89:535-613.

Smith, D.W., and Saunders, B.E. 1994. Personality characteristics of father/ 
Washington, DC 20531

Official Business

Penalty for Private Use $\$ 300$

perpetrators and non-offending mothers in incest families. Paper presented at the San Diego Conference on Maltreatment of Children, San Diego, CA, 1994.

Steffensmeier, D., and Motivans, M. 2000. Older men and older women in the arms of criminal law: Offending patterns and sentencing outcomes. Journal of Gerontology 5(3):141-151.

Steffensmeier, D., and Ulmer, J. 1995. Age differences in sentencing. Justice Quarterly 12(3):583-601.

Steffensmeier, D., Ulmer, J., and Kramer, J. 1998. The interaction of race, gender, and age in criminal sentencing: The punishment costs of being young, black, and male. Criminology 36(4):763-793.

Toch, H. 1977. Living in Prison. New York, NY: Macmillan Publishing, Inc.
U.S. Department of Justice, Bureau of Justice Statistics and Federal Bureau of Prisons. 2000. Survey of Inmates in State and Federal Correctional Facilities, 1997. (Computer file.) Compiled by U.S. Department of Commerce, Bureau of the Census. Ann Arbor, MI: Inter-university Consortium for Political and Social Research (producer and distributor).

Wolfe, J. 1998. Maine courts show leniency for child killers. Maine Sunday Telegram (July 12):1.

Zhang, J., and Yu, K.F. 1998. What's the relative risk? A method of correcting the odds ratios in cohort studies of common outcomes. Journal of the American Medical Association 280(19):1690-1691.
This Bulletin was prepared under grant numbers 98-JN-FX-0012 and 2000-JW-VX-0005 from the Office of Juvenile Justice and Delinquency Prevention, U.S. Department of Justice.

Points of view or opinions expressed in this document are those of the authors and do not necessarily represent the official position or policies of OJJDP or the U.S. Department of Justice.

The Office of Juvenile Justice and Delinquency Prevention is a component of the Office of Justice Programs, which also includes the Bureau of Justice Assistance, the Bureau of Justice Statistics, the National Institute of Justice, and the Office for Victims of Crime.

\section{Acknowledgments}

This Bulletin was prepared by David Finkelhor, Ph.D., Professor of Sociology, and Director, Crimes against Children Research Center, University of New Hampshire, david.finkelhor@unh.edu (e-mail); and Richard Ormrod, Ph.D., Research Professor, Crimes against Children Research Center, University of New Hampshire, rormrod@cisunix.unh.edu (e-mail). 